\title{
BMJ Open Incidence and mortality of fractures by frailty level over 80 years of age: cohort study using UK electronic health records
}

\author{
Rathi Ravindrarajah, ${ }^{1}$ Nisha C Hazra, ${ }^{1}$ Judith Charlton, ${ }^{1}$ Stephen H D Jackson, ${ }^{2}$ \\ Alex Dregan, ${ }^{1,2,3}$ Martin C Gulliford ${ }^{1,2,3}$
}

To cite: Ravindrarajah $\mathrm{R}$, Hazra NC, Charlton J, et al. Incidence and mortality of fractures by frailty level over 80 years of age: cohort study using UK electronic health records. BMJ Open 2018;8:e018836. doi:10.1136/ bmjopen-2017-018836

- Prepublication history for this paper is available online. To view these files, please visit the journal online (http://dx.doi. org/10.1136/bmjopen-2017018836).

Received 25 July 2017 Revised 12 September 2017 Accepted 9 0ctober 2017

Check for updates

${ }^{1}$ Department of Primary Care and Public Health Sciences,

King's College London, London, UK

${ }^{2}$ National Institute for Health Research Biomedical Research Centre at Guy's and St Thomas' National Health Service

Foundation Trust, Kings' College

London, London, UK

${ }^{3}$ Department of Clinical

Gerontology, King's College

London, London, UK

Correspondence to

Dr Rathi Ravindrarajah;

rathi.ravindrarajah@kcl.ac.uk

\section{ABSTRACT}

Objective This study aimed to estimate the association of frailty with incidence and mortality of fractures at different sites in people aged over 80 years.

Design Cohort study.

Setting UK family practices from 2001 to 2014.

Participants 265195 registered participants aged 80 years and older.

Measurements Frailty status classified into 'fit', 'mild', 'moderate' and 'severe' frailty. Fractures, classified into non-fragility and fragility, including fractures of femur, pelvis, shoulder and upper arm, and forearm/wrist. Incidence of fracture, and mortality within 90 days and 1 year, were estimated.

Results There were 28643 fractures including: nonfragility fractures, 9101; femur, 12 501; pelvis, 2172; shoulder and upper arm, 4965; and forearm/wrist, 6315. The incidence of each fracture type was higher in women and increased with frailty category (femur, severe frailty compared with 'fit', incidence rate ratio (IRR) $2.4,95 \% \mathrm{Cl}$ 2.3 to 2.6). Fractures of the femur (95-99 years compared with $80-84$ years, IRR $2.7,95 \% \mathrm{Cl} 2.6$ to 2.9 ) and pelvis (IRR $2.9,95 \% \mathrm{Cl} 2.5$ to 3.3 ) were strongly associated with age but non-fragility and forearm fractures were not. Mortality within 90 days was greatest for femur fracture (adjusted HR, compared with forearm fracture 4.3, 95\% Cl 3.7 to 5.1). Mortality was higher in men and increased with age (HR 5.3, 95\% Cl 4.3 to 6.5 in those over 100 years compared with 80-84 years) but was less strongly associated with frailty category. Similar associations with fractures were seen at 1-year mortality.

Conclusions The incidence of fractures at all sites was higher in women and strongly associated with advancing frailty status, while the risk of mortality after a fracture was greater in men and was associated with age rather than frailty category.

\section{INTRODUCTION}

Fractures in older people are a huge public health challenge as immediate complications and longer-term declines in health status may lead to hospital admissions, increased care needs and a reduction in the quality of life. ${ }^{1}$ Previous studies suggest that frailty may be associated with increased risk of fracture, ${ }^{2-5}$ but few studies have reported on the

\section{Strengths and limitations of this study}

The study had the strengths of a large, longitudinal and nationally representative sample of the general population registered in primary care.

- Limitations of the study include possible misclassification of fractures sites in clinical records.

- A clear distinction between 'fragility' and 'nonfragility' fractures may not always be possible because either type of fracture may occur at the same site.

- We did not have information on the type of medical care and rehabilitation services or hospital site at which individuals were treated, which might be associated with outcomes following a fracture. These merit investigation in future studies.

incidence of fracture, and mortality following fracture, at different sites.

The frailty syndrome is characterised by dysregulation in multiple body systems resulting in homoeostatic imbalances that may eventually lead to adverse outcomes such as falls, fractures, disability, institutionalisation, hospitalisation and mortality. ${ }^{2}$ Several attempts have been made to operationalise the concept of frailty with the most widely used models including frailty phenotype ${ }^{6}$ a physical syndrome consisting of five physical characteristics and Frailty Index, ${ }^{7}$ which views frailty as an accumulation of deficits. The literal meaning of being frail means to 'break easily' suggesting that frail individuals are more likely to experience fractures. ${ }^{8}$ In addition to age-related decline in bone mass, ageing individuals tend to develop balance and gait problems and are more likely to fall and experience a fracture. ${ }^{9}$ Frailty Indices are increasingly used to predict clinical outcomes in older people, ${ }^{10}$ but associations of frailty with fracture may be partially tautological if falls and fractures are included in the assessment of frailty. ${ }^{11}$

Fragility fractures are those that occur from mechanical forces that do not usually 
Table 1 Number and incidence of fractures by fracture site, gender, age group and frailty status

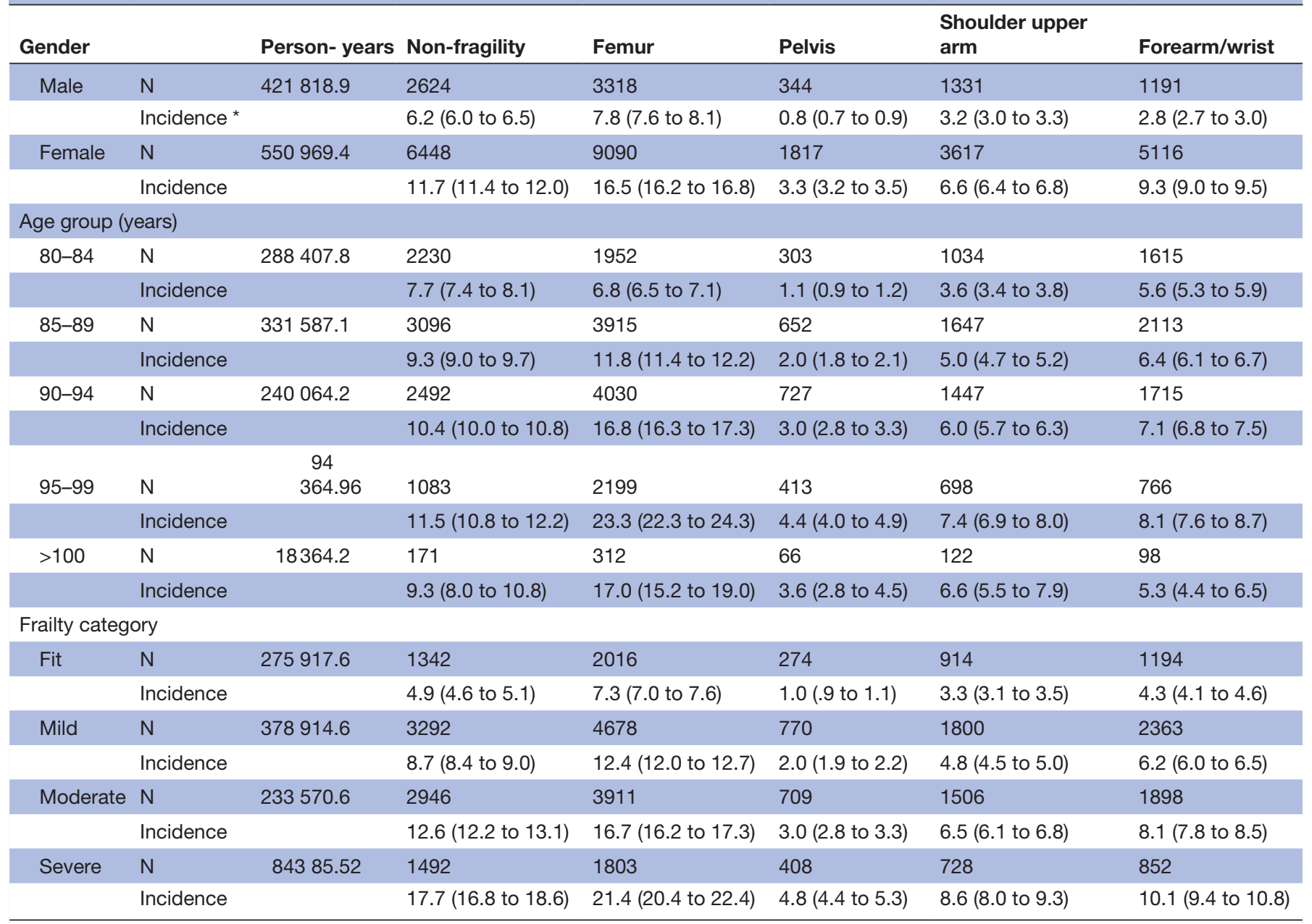

${ }^{*}$ Incidence rates are per 1000 person-years $(95 \% \mathrm{Cl})$.

cause a fracture, and these are known as low-energy or low-level trauma, such as falls resulting from a standing height. Fragility fractures are often a sign of osteoporosis and common in the elderly and these create problems in activities of daily living, physical function, disability, pain, fear of falling and increased mortality. ${ }^{12}$ It has been estimated that the medical costs from fragility fractures in the UK were about $£ 1.8$ billion in 2000 , with a possible increase to $£ 2.2$ billion by $2025 .^{13}$

This study aimed to add to our understanding of the effect of frailty on patients with fractures are different sites. We aimed to evaluate the risk that frailty status poses for fractures at different sites, estimating the association of frailty with both the incidence and mortality associated with fractures at different sites in people aged more than 80 years.

\section{METHODS}

\section{Data source}

This study drew on data from the Clinical Practice Research Datalink (CPRD), one of the world's largest databases of primary care electronic health records (EHRs), including approximately $7 \%$ of UK general practices, with anonymised data collected from 1990 to present. The registered active population of about 5 million is generally representative of the UK population in terms of age and sex. ${ }^{14}$ Data collected into CPRD comprise clinical diagnoses, records of blood pressure and other clinical measurements, prescriptions, results of investigations and referrals to specialist services. The CPRD has broad National Research Ethics Service Committee ethics approval for observational research studies.

\section{Study design and participants}

We drew a random sample of participants who had their 80th, 85th, 90th, 95th and 100th birthdays while registered in CPRD between 1990 and 2014 including a maximum of 50000 each of men and women, with replacement, in each age group. There were less than 50000 men and 50000 women eligible in the older age groups, and after accounting for participants sampled in more than one age group, the total sample comprised 299495 participants. Participants entered the analysis at the age they were sampled. To focus on a more recent period, the present analysis was restricted to 265195 participants, who were registered between 1 January 2001 and 31 December 2009 with latest follow-up at 31 December 2014. Fracture 
Fracture Incidence by Gender

\begin{tabular}{|c|c|c|c|c|c|c|}
\hline FEMUR & Fractures & PYears & & IRR & LL & UL \\
\hline Male & 3,318 & 421,819 & & Ref. & & \\
\hline Female & 9,090 & 550,969 & $\square$ & 1.86 & 1.78 & 1.94 \\
\hline \multicolumn{7}{|l|}{ PELVIS } \\
\hline Male & 344 & 421,819 & & Ref. & & \\
\hline Female & 1,817 & 550,969 & & 3.53 & 3.14 & 3.97 \\
\hline \multicolumn{7}{|c|}{ SHOULDER / UPPER ARM } \\
\hline Male & 1,331 & 421,819 & & Ref. & & \\
\hline Female & 3,617 & 550,969 & $\mathbf{E}$ & 1.94 & 1.81 & 2.07 \\
\hline \multicolumn{7}{|c|}{ FOREARM / WRIST } \\
\hline Male & 1,191 & 421,819 & & Ref. & & \\
\hline Female & 5,116 & 550,969 & & 3.21 & 3.01 & 3.42 \\
\hline \multicolumn{7}{|c|}{ NON-FRAGILITY } \\
\hline Male & 2,624 & 421,819 & & Ref. & & \\
\hline \multirow[t]{2}{*}{ Female } & 6,448 & 550,969 & 口 & 1.80 & 1.70 & 1.90 \\
\hline & & & $\begin{array}{l}2.0 \\
\text { Rater }\end{array}$ & & & \\
\hline
\end{tabular}

Figure 1 Incidence rate ratio (IRR) for fractures by site and gender. Estimates are adjusted for age group and frailty status. LL, lower Level; UL, upper level.

incidence was calculated in the 265195 participants in those who had a fracture within the study period. In participants who had the same type of fracture recorded within 12 months of the first fracture, the fracture record was excluded. To calculate the risk of mortality after the first fracture only participants with the first fracture were considered which included 28643 patients. Individuals with multiple fractures recorded on the same day were excluded which resulted in a cohort of 24168 participants. Deaths from any cause was determined from CPRD records. The risk of mortality was assessed in participants up to 90 days and 1 year of the first fracture.

\section{Main measures}

An index of frailty status was calculated for each participant using a previously described electronic Frailty Index (eFI). ${ }^{11}$ The eFI was defined based on a cumulative deficit model, which accounts for the number of deficits present in an individual. ${ }^{15}$ The eFI is calculated based on the assessment of 36 potential deficits as reported by Clegg et $a l .{ }^{11}$ For the present analyses, we omitted falls and fractures from the assessment of frailty, as fractures were the outcome and falls were closely associated with fractures. We also omitted quantitative traits and polypharmacy from the assessment of frailty. The eFI score was calculated by the presence or absence of individual deficits as a proportion of the total possible based on medical diagnoses recorded during the first 12 months of follow-up. Categories of fit, mild, moderate and severe frailty were defined following Clegg et al. ${ }^{11}$

The occurrence of fractures was assessed from records of medical diagnostic codes recorded into patients' EHRs. We adapted the categorisation used by Torstensson et $a l^{16}$ to categorise fractures into 'non-fragility' and 'fragility' fractures. Fragility fractures most commonly occur in the femur, pelvis, shoulder and upper arm, and forearm and wrist. ${ }^{1617}$ Other fractures which were not coded into these categories were coded as non-fragility fractures. Records of fracture at the same site within a 12-month period were assumed to refer to a single fracture. Participants with fractures at more than one site recorded on the same date were omitted from the mortality analysis.

\section{Statistical analysis}

Incidence rates (IRs) for each type of fracture were estimated using person time for all registered patients as the denominator. Poisson regression was employed to estimate adjusted incidence rate ratios (IRRs) and their CIs. 
Fracture Incidence by Age-group (years)

\begin{tabular}{|c|c|c|c|c|c|c|}
\hline FEMUR & Fractures & PYears & & IRR & LL & UL \\
\hline $80-84$ & 1,952 & 288,408 & & Ref. & & \\
\hline $85-89$ & 3,915 & 331,587 & 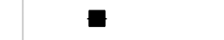 & 1.59 & 1.50 & 1.68 \\
\hline $90-94$ & 4,030 & 240,064 & $\mathbf{\square}$ & 2.14 & 2.03 & 2.26 \\
\hline $95-99$ & 2,199 & 94,365 & - & 2.72 & 2.56 & 2.89 \\
\hline$>100$ & 312 & 18,364 & - & 2.17 & 1.92 & 2.44 \\
\hline \multicolumn{7}{|l|}{ PELVIS } \\
\hline $80-84$ & 303 & 288,408 & & Ref. & & \\
\hline $85-89$ & 652 & 331,587 & - & 1.62 & 1.41 & 1.86 \\
\hline $90-94$ & 727 & 240,064 & - & 2.28 & 1.99 & 2.61 \\
\hline $95-99$ & 413 & 94,365 & - & 2.83 & 2.43 & 3.30 \\
\hline$>100$ & 66 & 18,364 & $\longrightarrow$ & 2.58 & 1.98 & 3.37 \\
\hline \multicolumn{7}{|c|}{ LDER / UPPER ARM } \\
\hline $80-84$ & 1,034 & 288,408 & & Ref. & & \\
\hline $85-89$ & 1,647 & 331,587 & $\Rightarrow$ & 1.27 & 1.17 & 1.37 \\
\hline $90-94$ & 1,447 & 240,064 & - & 1.45 & 1.34 & 1.58 \\
\hline $95-99$ & 698 & 94,365 & 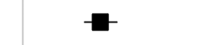 & 1.62 & 1.47 & 1.80 \\
\hline$>100$ & 122 & 18,364 & - & 1.56 & 1.30 & 1.90 \\
\hline \multicolumn{7}{|c|}{ REARM / WRIST } \\
\hline $80-84$ & 1,615 & 288,408 & & Ref. & & \\
\hline $85-89$ & 2,113 & 331,587 & E & 1.04 & 0.97 & 1.11 \\
\hline $90-94$ & 1,715 & 240,064 & - & 1.09 & 1.02 & 1.17 \\
\hline $95-99$ & 766 & 94,365 & $\square$ & 1.05 & 0.96 & 1.15 \\
\hline$>100$ & 98 & 18,364 & $\leftarrow$ & 0.73 & 0.60 & 0.90 \\
\hline \multicolumn{7}{|c|}{ ON-FRAGILITY } \\
\hline $80-84$ & 2,230 & 288,408 & & Ref. & & \\
\hline $85-89$ & 3,096 & 331,587 & $\square$ & 1.10 & 1.00 & 1.10 \\
\hline $90-94$ & 2,492 & 240,064 & $\boldsymbol{E}$ & 1.10 & 1.10 & 1.20 \\
\hline $95-99$ & 1,083 & 94,365 & - & 1.20 & 1.10 & 1.20 \\
\hline$>100$ & 171 & 18,364 & - & 1.00 & 0.90 & 1.20 \\
\hline & & & 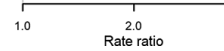 & & & \\
\hline
\end{tabular}

Figure 2 Incidence rate ratio (IRR) for fractures by site and age group. Estimates are adjusted for gender and frailty status. LL, lower Level; UL, upper level.

Covariates included site of fracture, gender, age group and frailty status. Mortality within 90 days of the occurrence of a first fracture was estimated in a time-to-event framework as previous evidence has shown the mortality rate after a fracture is highest within 90 days of the fracture. ${ }^{18}$ We also explored 1-year mortality after a fracture. The Cox proportional hazards model was employed to estimate adjusted HRs for mortality within 90 days and 1 year of fracture by site, age group, gender and frailty status. Statistical analysis was carried out using STATA V.14 and forest plots were constructed using the 'forestplot' package in the $\mathrm{R}$ programme.

\section{RESULTS}

The incidence cohort comprised 265195 patients, including 116394 (43.9\%) men and 148801 (56.1\%) women aged 80 years and over between 2001 and 2014. There were 28643 patients, with 34896 fractures including: non-fragility, 9072; femur, 12 408; pelvis, 2161; shoulder and upper arm, 4948; and forearm/wrist, 6307.

Table 1 presents the number of fractures and IRs by gender, age group and frailty category. Rates of fracture were generally higher in women than men, with femur fracture being the most frequent fracture type. The overall incidence of femur fracture in women was 16.5 per 1000 participant years (95\% CI 16.2 to 16.8 ). Pelvic fractures in men were least frequent with a rate of 0.8 (95\% CI 0.7 to 0.9 ) per 1000 participant years. The incidence of fracture at each site showed a graded increase with advancing frailty category. The incidence of non-fragility fracture increased from 4.9 (95\% CI 4.6 to 5.1 ) in 'fit' individuals to 8.7 (95\% CI 8.4 to 9.0 ) in 'mild' frailty, 12.6 (95\% CI 12.2 to 13.1) in 'moderate' frailty and 17.7 (95\% CI 16.8 to 18.6) in 'severe' frailty, with similar trends being observed for fragility fractures.

Figure 1 presents adjusted IRRs for each fracture type by gender. The incidence of all types of fractures was 


\section{Fracture Incidence by Frailty Category}

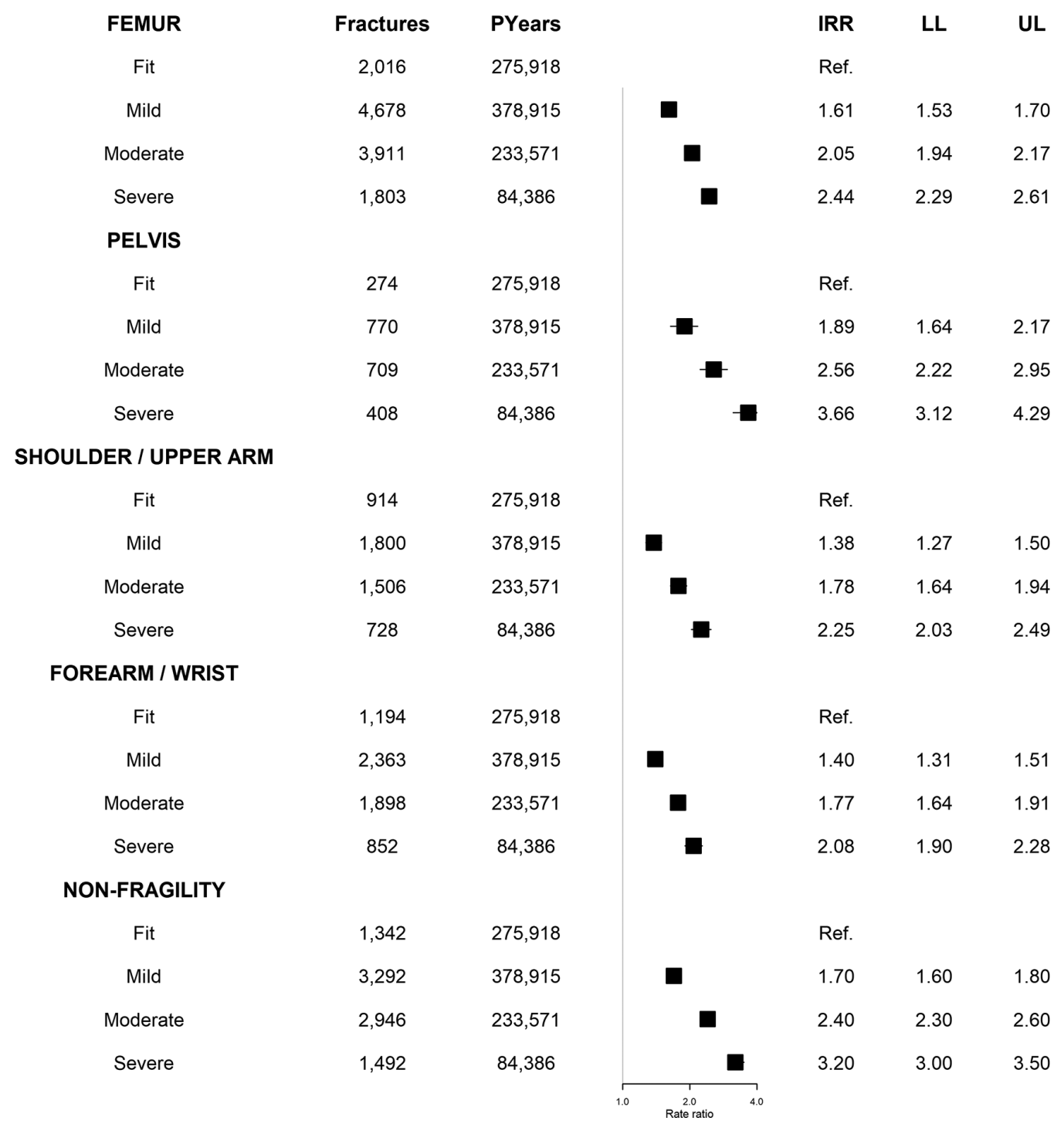

Figure 3 Incidence rate ratio (IRR) for fractures by site and frailty status. Estimates are adjusted for gender and age group. LL, lower Level; UL, upper level.

higher in women compared with men, with the highest IRRs being for fragility fractures including pelvic fracture (IRR 3.5, 95\% CI 3.1 to 4.0 ), followed by fractures of forearm/wrist (IRR 3.2). Non-fragility fractures showed a lower IRR of 1.8 (95\% CI 1.7 to 1.9 ) in women compared with men. Figure 2 represents adjusted IRR by age group, and figure 3 presents IRR by frailty status. The incidence of each type of fracture increased with frailty status. Compared with those in the fit group, those who were severely frail had an IRR for pelvic fracture of 3.7 (95\% CI 3.1 to 4.3$)$ and for non-fragility 3.2 (95\% CI 3.0 to 3.5 ). The incidence of femur, pelvic and shoulder upper arm fractures increased with age, but there was a slight decrease in the incidence of these fractures in the $100+$ age group. Fractures of the forearm and wrist and non-fragility fractures showed negligible association with age group after adjusting for gender and frailty category.
After excluding 4475 patients with fractures at more than one site on the same date, the mortality cohort consisted of 24168 participants. There were 2865 deaths (men 934; women 1931) within 90 days of a fracture (table 2). Mortality was higher in men $(14.1 \%)$ compared with women $(11.5 \%)$ irrespective of fracture site. Femur fracture was associated with highest mortality (men $22.4 \%$; women $17.9 \%$ ) while fractures of the forearm/ wrist were associated with lowest mortality (men $4.5 \%$; women $4.2 \%$ ). A similar trend was seen for all types of fractures. Mortality at all sites was generally only weakly associated with increasing frailty category (fit, $10.6 \%$; severe frailty $13.6 \%$ ).

The risk of mortality after 90 days of fracture was highest in those who had a femur fracture, compared with those who had a forearm/wrist fracture as reference, with a HR of 4.3 (95\% CI 3.7 to 5.1) (table 3). The risk of mortality was similar in those who had a non-fragility 
Table 2 90-day mortality by site of fracture and by gender, age group and frailty status

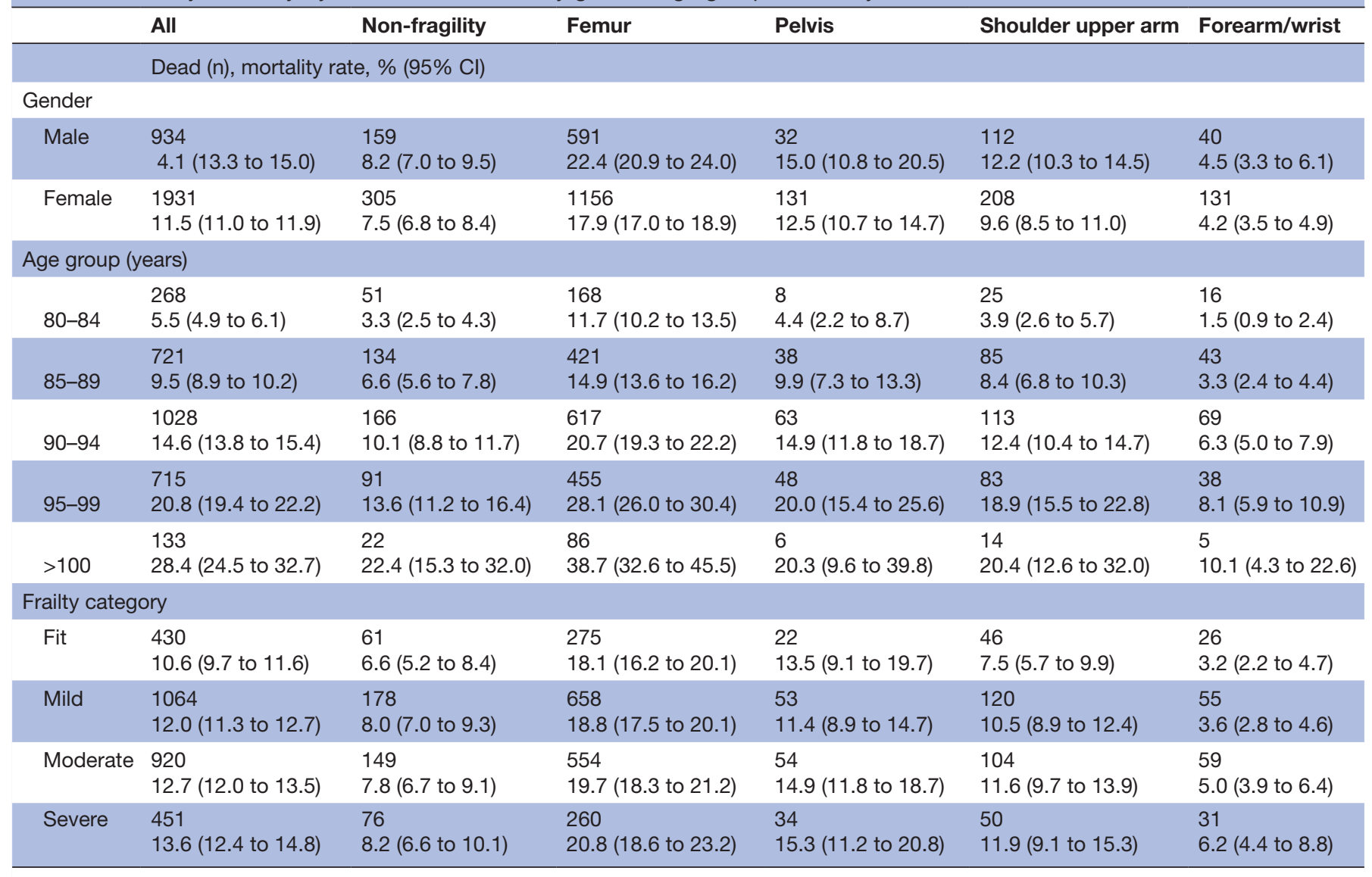

Figures are number of deaths. Mortality rate (\%), 95\% Cl.

fracture $(\mathrm{HR}=1.8)$ and shoulder and upper arm fracture $(\mathrm{HR}=2.3)$ compared with reference. Women had a lower risk of mortality after fracture compared with men with a HR of 0.7 (95\% CI 0.6 to 0.8 ). The risk of mortality after a fracture increased with age. Compared with those who were aged $80-84$, those who were aged $100+$ hada HR of 5.3 (95\% CI 4.3 to 6.5$)$. The risk of mortality after a fracture increased slightly with increase in frailty status although the association was significant only in those who were moderately and severely frail, that is, compared with those who were fit, those who were severely frail had a HR of 1.2 (95\% CI 1.1 to 1.4). Similar associations with mortality were observed after 1 year after a fracture, (see tables 4 and 5).

\section{DISCUSSION}

\section{Main findings}

In people aged 80 years or older, the incidence of fracture is strongly associated with increasing frailty and female gender, while mortality following fracture is generally greater in men and is more strongly associated with age than frailty status. Femur fractures are most frequent and more common in women and these were associated with highest mortality. The incidence of pelvis fracture was also higher in women and increased with age and frailty status. A similar trend was observed with a shoulder upper arm and femur fractures. The incidence of forearm/wrist fracture incidence was low and was significantly lower in those who were aged 100 years and over. The risk of mortality in those who had a fracture increased with age and the trend was seen for all types of fractures. A similar association was seen with increase in frailty status.

\section{Strengths and limitations}

The study has several strengths, including a large, longitudinal and nationally representative sample of the general population registered in primary care. Previous research on CPRD data have validated the conditions recorded in CPRD and it has been suggested the findings to be generalised to the UK population. ${ }^{19}{ }^{20}$ We calculated IRs of fracture using the first occurrence of a single type of fracture in any study year. Repeat records of fractures of the same type in the same year were omitted as it is possible that duplicate information about the same event might have been recorded in CPRD. However, this might lead to slight underestimation of true IRs. Fracture sites might sometimes be miscoded, although previous data suggest that records of hip and vertebral fractures are valid in CPRD. ${ }^{21}$ It is also possible there were errors in the date of fracture recorded, if patients were admitted to hospital and general practitioner records updated later. We caution that a clear distinction cannot always be made between 'fragility' and 'non-fragility' fractures because 
Table 3 HRs' 90-day mortality after their fracture by fracture type, gender, age group and frailty status

\begin{tabular}{|c|c|c|c|c|}
\hline & $\mathbf{n}$ & Dead & HR (95\% Cls) & $P$ value \\
\hline Non-fragility & 6132 & 464 & 1.8 (1.5 to 2.13$)$ & $<0.001$ \\
\hline Femur & 9409 & 1747 & 4.3 (3.7 to 5.06 ) & $<0.001$ \\
\hline Shoulder upper arm & 3166 & 320 & 2.3 (1.9 to 2.79 ) & $<0.001$ \\
\hline Forearm wrist & 4133 & 171 & Reference & \\
\hline Male & 6788 & 934 & Reference & \\
\hline Female & 17380 & 1931 & 0.7 (0.6 to 0.8$)$ & $<0.001$ \\
\hline \multicolumn{5}{|l|}{ Age group (years) } \\
\hline $80-84$ & 5010 & 268 & Reference & \\
\hline 85-89 & 7795 & 721 & $1.6(1.4$ to 1.8$)$ & $<0.001$ \\
\hline$>100$ & 488 & 133 & 5.3 (4.3 to 6.5$)$ & $<0.001$ \\
\hline \multicolumn{5}{|l|}{ Frailty category } \\
\hline Fit & 4155 & 430 & Reference & \\
\hline Mild & 9114 & 1064 & $1.1(1.0$ to 1.2$)$ & 0.148 \\
\hline Moderate & 7468 & 920 & 1.1 (1.0 to 1.3$)$ & 0.028 \\
\hline Severe & 3431 & 451 & 1.2 (1.1 to 1.4$)$ & 0.003 \\
\hline
\end{tabular}

either type of fracture may occur at the same site. In order to facilitate comparison with previous research, we adopted a classification reported in a previous study. ${ }^{16} \mathrm{We}$ did not explore usage of preventive medical interventions for osteoporosis as this was beyond the scope of our study. We also did not have information on the type of medical care and rehabilitation services or hospital site at which individuals were treated, which might be associated with outcomes following a fracture. These merit investigation in future studies.

\section{Comparison with other studies}

Previous studies show that the incidence of fractures is higher in women than in men. ${ }^{22-24}$ A previous study in a cohort based in Leicestershire also showed that the incidence of all fractures increased with age, but the study included participants of all ages with individuals aged 85 and over grouped together. ${ }^{25}$ The incidence of forearm fractures has been reported to be higher in women. ${ }^{24} 2627$ In UK, adults aged 50 years and over the incidence of radius/ulna fractures were higher in women. In the period between 1990 and 2012, the incidence of forearm fractures remained stable in men but decreased in women. ${ }^{28}$ Requena et $a l^{29}$ compared the IRs and trends of fractures in five European countries (Denmark, Germany, the Netherlands, Spain and UK) using electronic healthcare record databases. They showed that the incidence of hip and femur fractures increased exponentially with age for both men and women. Although their data didn't explore the 100+ age group, our findings showed a reduction in incidence for both pelvic and femur fractures in this age group. The study of osteoporotic fractures in women showed that frailty was significantly associated with hip fractures but only weakly related to other types of fractures which was different to our findings. It may be possible these differences in the findings may be due to the fact frailty was assessed by a frailty phenotype model and the cohort being women aged 65-79 years, might be a few reasons for the discrepancies. ${ }^{22}$ Factors associated with frailty such as weight loss, ${ }^{23}$ inflammation ${ }^{24}$ sarcopenia, ${ }^{25}$ hormones, ${ }^{26}$ cognitive decline and depression ${ }^{27}$ maybe contributing towards the increased incidence of fractures seen in frail individuals.

Previous studies suggest that $20 \%$ of patients with a hip fracture die within 1 year. ${ }^{3031}$ Our findings of men having higher mortality for all types of fractures was consistent with the findings in the Dubbo Osteoporosis Epidemiology Study, which showed that men who were $\geq 60$ years and who had a fracture of any type had a higher risk of age-standardised mortality than women. ${ }^{32}$ Similar results of an increased mortality risk after a fracture has been shown in other studies with the risk of mortality associated with age, location of fracture and gender with males having a higher risk of mortality after a fracture. ${ }^{1}$ Our results show a higher incidence of fractures with increase in frailty and the likelihood of mortality within 90 days of the fracture also increased with increase in frailty status, although the relationship was stronger with increase in age than frailty status. Although the incidence of fractures decreased in the $100+$ age group mortality rates after a fracture showed an exponential rise in the age groups. 
Open Access

Table 4 One-year mortality by site of fracture and by gender, age group and frailty status

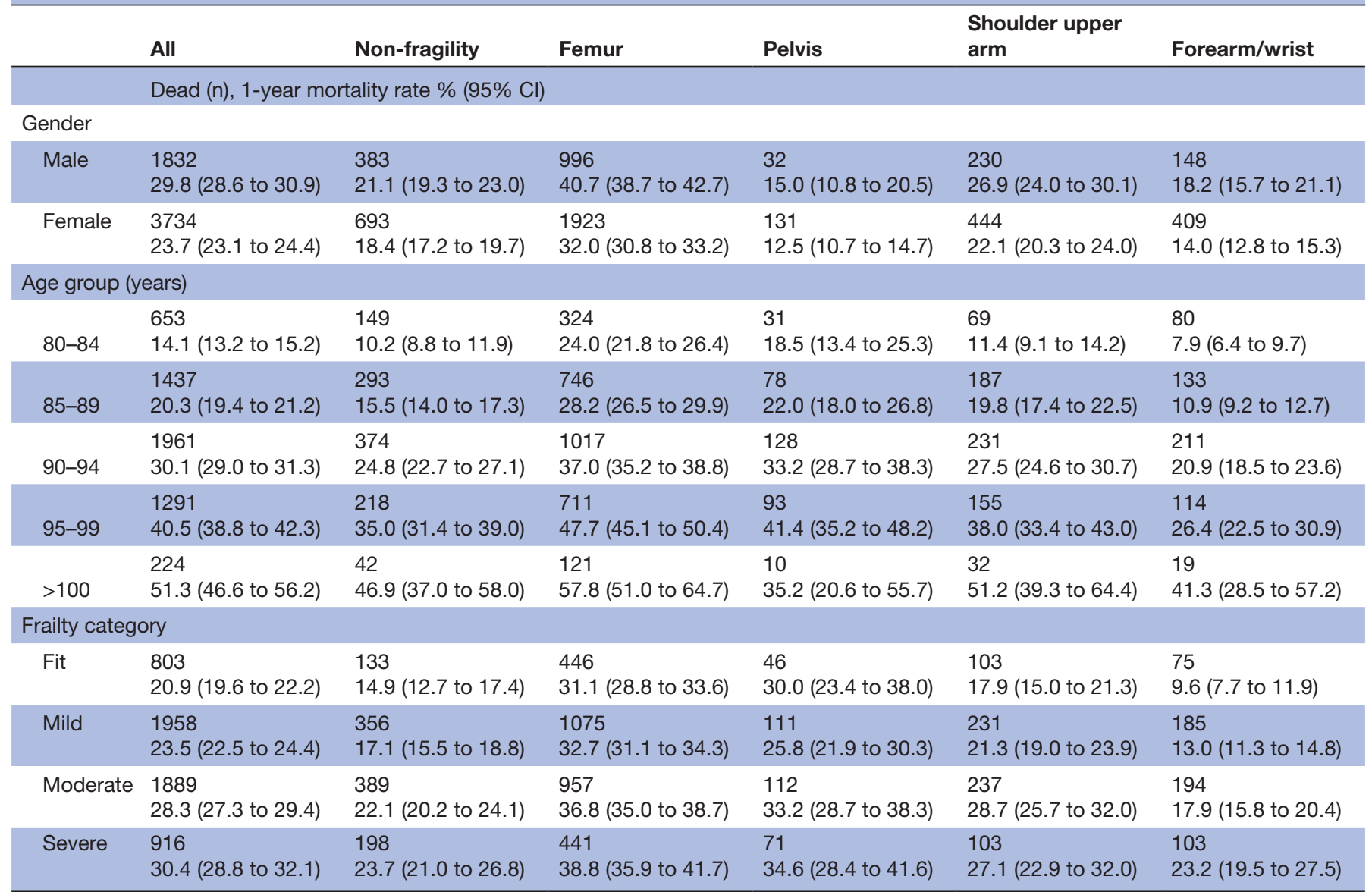

Figures are number of deaths. Mortality rate (\%), 95\% Cl.

Table 5 HRs' 1-year mortality after their fracture by fracture type, gender, age group and frailty status

\begin{tabular}{|c|c|c|c|c|}
\hline & $\mathbf{n}$ & Dead & HR (95\% Cls) & $P$ value \\
\hline Non-fragility & 6132 & 1076 & 1.3 (1.2 to 1.4$)$ & $<0.001$ \\
\hline Femur & 9409 & 2919 & 2.5 (2.3 to 2.7 ) & $<0.001$ \\
\hline Shoulder upper arm & 3166 & 674 & 1.6 (1.4 to 1.8$)$ & $<0.001$ \\
\hline Forearm wrist & 4133 & 557 & Reference & \\
\hline Female & 17380 & 3734 & 0.7 (0.6 to 0.7 ) & $<0.001$ \\
\hline \multicolumn{5}{|l|}{ Age group (years) } \\
\hline $80-84$ & 5010 & 653 & Reference & \\
\hline $85-89$ & 7795 & 1437 & 1.4 (1.3 to 1.5$)$ & $<0.001$ \\
\hline \multicolumn{5}{|l|}{ Frailty category } \\
\hline Fit & 4155 & 803 & Reference & \\
\hline Mild & 9114 & 1958 & 1.1 (1.0 to 1.2$)$ & 0.058 \\
\hline Moderate & 7468 & 1889 & 1.3 (1.2 to 1.4$)$ & $<0.001$ \\
\hline Severe & 3431 & 916 & $1.4(1.3$ to 1.5$)$ & $<0.001$ \\
\hline
\end{tabular}


The incidence of fractures reducing in the older age groups observed in the centenarians may be due to difference in bone mineral density and a reduced tendency to fall due to increased social support. ${ }^{23}$ The underlying comorbidities of the individual might be the reason for the increased mortality observed in individuals after fracture, this might also explain the association between higher risk of mortality after a fracture and an increase in frailty status. ${ }^{183-35}$

\section{CONCLUSION}

This research highlights the public health impact of fractures in association with frailty in older adults. Research is needed to understand factors that are associated with increased risk of fractures in the elderly in order to inform fracture prevention strategies. ${ }^{29}$ Mortality remains high and most of those who have fractures are unlikely to regain prior physical performance. ${ }^{36}{ }^{37}$ Evidence is needed to improve fracture and postfracture management in order to optimise the outcomes following fracture in frail older adults. ${ }^{38} 39$

Contributors RR designed, contributed to data analysis and drafted the paper. MCG supervised and assisted with draft and conclusions. JC contributed to data analysis. NCH, SHDJ and AD contributed to the write up and conclusions. All authors read and approved the final manuscript.

Funding This work was supported by the Dunhill Medical Trust (grant no R392/1114). MCG and AD were supported by the National Institute for Health Research (NIHR) Biomedical Research Centre at Guy's and St Thomas' NHS Foundation Trust and King's College London.

\section{Competing interests None declared.}

Patient consent Detail has been removed from this case description/these case descriptions to ensure anonymity. The editors and reviewers have seen the detailed information available and are satisfied that the information backs up the case the authors are making.

Ethics approval The protocol for this study received scientific and ethic al approval from the Independent Scientific Advisory Committee for CPRD studies (ISAC Protocol 13_151).

Provenance and peer review Not commissioned; externally peer reviewed.

Data sharing statement Since data ownership belongs to CPRD, data sharing is not possible.

Open Access This is an Open Access article distributed in accordance with the Creative Commons Attribution Non Commercial (CC BY-NC 4.0) license, which permits others to distribute, remix, adapt, build upon this work non-commercially, and license their derivative works on different terms, provided the original work is properly cited and the use is non-commercial. See: http://creativecommons.org/ licenses/by-nc/4.0/

(C) Article author(s) (or their employer(s) unless otherwise stated in the text of the article) 2018. All rights reserved. No commercial use is permitted unless otherwise expressly granted.

\section{REFERENCES}

1. van den Bergh JP, van Geel TA, Geusens PP, Osteoporosis GPP. Osteoporosis, frailty and fracture: implications for case finding and therapy. Nat Rev Rheumatol 2012;8:163-72.

2. Ensrud KE, Ewing SK, Taylor BC, et al. Comparison of 2 frailty indexes for prediction of falls, disability, fractures, and death in older women. Arch Intern Med 2008;168:382-9.

3. Ensrud KE, Ewing SK, Taylor BC, et al. Frailty and risk of falls, fracture, and mortality in older women: the study of osteoporotic fractures. J Gerontol A Biol Sci Med Sci 2007;62:744-51.
4. Chen JS, Simpson JM, March LM, et al. Fracture risk assessment in frail older people using clinical risk factors. Age Ageing 2008;37:536-41.

5. Chen JS, Cameron ID, Simpson JM, et al. Low-trauma fractures indicate increased risk of hip fracture in frail older people. $J$ Bone Miner Res 2011;26:428-33.

6. Fried LP, Tangen CM, Walston J, et al. Frailty in older adults: evidence for a phenotype. J Gerontol A Biol Sci Med Sci 2001;56:M146-M157.

7. Rockwood K, Mitnitski A. Frailty defined by deficit accumulation and geriatric medicine defined by frailty. Clin Geriatr Med 2011;27:17-26.

8. Rolland $\mathrm{Y}$, Abellan van Kan G, Bénétos A, et al. Frailty, osteoporosis and hip fracture: causes, consequences and therapeutic perspectives. J Nutr Health Aging 2008;12:a319-a330.

9. Morley JE. Falls and fractures. J Am Med Dir Assoc 2007;8:276-8.

10. Krishnan M, Beck S, Havelock W, et al. Predicting outcome after hip fracture: using a frailty index to integrate comprehensive geriatric assessment results. Age Ageing 2014;43:122-6.

11. Clegg A, Bates C, Young J, et al. Development and validation of an electronic frailty index using routine primary care electronic health record data. Age Ageing 2016;45:353-60.

12. Giangregorio L, Thabane L, Cranney A, et al. Osteoporosis knowledge among individuals with recent fragility fracture. Orthop Nurs 2010;29:99-107.

13. Burge RT, Worley D, Johansen A, et al. The cost of osteoporotic fractures in the UK: projections for 2000-2020. J Med Econ 2001;4(1-4):51-62.

14. Herrett E, Gallagher AM, Bhaskaran K, et al. Data Resource Profile: Clinical Practice Research Datalink (CPRD). Int J Epidemiol 2015;44:827-36.

15. Clegg A, Young J, lliffe S, et al. Frailty in elderly people. The Lancet 2013;381:752-62.

16. Torstensson M, Hansen AH, Leth-Møller K, et al. Danish registerbased study on the association between specific cardiovascular drugs and fragility fractures. BMJ Open 2015;5:e009522.

17. Sporer SM, Weinstein JN, Koval KJ. The geographic incidence and treatment variation of common fractures of elderly patients. $J \mathrm{Am}$ Acad Orthop Surg 2006;14:246-55.

18. Liem IS, Kammerlander C, Raas $\mathrm{C}$, et al. Is there a difference in timing and cause of death after fractures in the elderly? Clin Orthop Relat Res 2013;471:2846-51.

19. Herrett EL, Thomas SL, Smeeth L. Validity of diagnoses in the general practice research database. Br J Gen Pract 2011;61:438-9.

20. Jick SS, Kaye JA, Vasilakis-Scaramozza C, et al. Validity of the general practice research database. Pharmacotherapy 2003;23:686-9.

21. Van Staa TP, Abenhaim L, Cooper C, et al. The use of a large pharmacoepidemiological database to study exposure to oral corticosteroids and risk of fractures: validation of study population and results. Pharmacoepidemiol Drug Saf 2000;9:359-66.

22. van Staa TP, Dennison EM, Leufkens HG, et al. Epidemiology of fractures in England and Wales. Bone 2001;29:517-22.

23. Knowelden J, BUHR AJ, Dunbar O. Incidence of Fractures in Persons over 35 Years of Age A Report to the M.R.C. Working Party on Fractures in the Elderly. Br J Prev Soc Med 1964;18:130-41.

24. Singer BR, McLauchlan GJ, Robinson CM, et al. Epidemiology of fractures in 15000 adults. The Influence Of Age And Gender 1998;80:243-8.

25. Donaldson LJ, Cook A, Thomson RG. Incidence of fractures in a geographically defined population. $J$ Epidemiol Community Health 1990;44:241-5.

26. Curtis EM, van der Velde R, Moon RJ, et al. Epidemiology of fractures in the United Kingdom 1988-2012: Variation with age, sex, geography, ethnicity and socioeconomic status. Bone 2016;87:19-26.

27. Ismail AA, Pye SR, Cockerill WC, et al. Incidence of limb fracture across Europe: results from the European Prospective Osteoporosis Study (EPOS). Osteoporos Int 2002;13:565-71.

28. van der Velde RY, Wyers CE, Curtis EM, et al. Secular trends in fracture incidence in the UK between 1990 and 2012. Osteoporos Int 2016;27:3197-206.

29. Requena G, Abbing-Karahagopian V, Huerta C, et al. Incidence rates and trends of hip/femur fractures in five European countries: comparison using e-healthcare records databases. Calcif Tissue Int 2014;94:580-9.

30. Braithwaite RS, Col NF, Wong JB. Estimating hip fracture morbidity, mortality and costs. J Am Geriatr Soc 2003;51:364-70.

31. Leibson CL, Tosteson AN, Gabriel SE, et al. Mortality, disability, and nursing home use for persons with and without hip fracture: a population-based study. J Am Geriatr Soc 2002;50:1644-50. 
32. Center JR, Nguyen TV, Schneider D, et al. Mortality after all major types of osteoporotic fracture in men and women: an observational study. Lancet 1999;353:878-82.

33. Cooper C, Atkinson EJ, Jacobsen SJ, et al. Population-based study of survival after osteoporotic fractures. Am J Epidemiol 1993;137:1001-5.

34. Johnell O, Kanis JA, Odén A, et al. Mortality after osteoporotic fractures. Osteoporos Int 2004;15:38-42.

35. Abrahamsen B, van Staa T, Ariely R, et al. Excess mortality following hip fracture: a systematic epidemiological review. Osteoporos Int 2009;20:1633-50.

36. Foster MR, Heppenstall RB, Friedenberg ZB, et al. A prospective assessment of nutritional status and complications in patients with fractures of the hip. J Orthop Trauma 1990;4:49-57.
37. Magaziner J, Simonsick EM, Kashner TM, et al. Predictors of functional recovery one year following hospital discharge for hip fracture: a prospective study. J Gerontol 1990;45:M101-M107.

38. Friedman SM, Mendelson DA, Kates SL, et al. Geriatric comanagement of proximal femur fractures: total quality management and protocol-driven care result in better outcomes for a frail patient population. J Am Geriatr Soc 2008;56:1349-56.

39. Prestmo A, Hagen G, Sletvold O, et al. Comprehensive geriatric care for patients with hip fractures: a prospective, randomised, controlled trial. Lancet 2015;385:1623-33. 